\title{
Bio-oil Production from Food Processing Residues: Improving the Bio-oil Yield and Quality by Aqueous Phase Recycle in Hydrothermal Liquefaction of Blackcurrant (Ribes nigrum L.) Pomace
}

\author{
Maxime Déniel, ${ }^{*},{ }^{\dagger}{ }^{\dagger}$ Geert Haarlemmer, ${ }^{\dagger}$ Anne Roubaud, ${ }^{\dagger}$ Elsa Weiss-Hortala, ${ }^{\ddagger}$ and Jacques Fages ${ }^{\ddagger}$ \\ ${ }^{\dagger}$ CEA-LITEN, Laboratoire de Thermo-conversion des Bioressources, 17 rue des Martyrs, 38054 Grenoble, France \\ ${ }^{\ddagger}$ Université de Toulouse, Ecole des Mines d'Albi, CNRS, Centre RAPSODEE, 81013 Albi, France
}

Supporting Information

\begin{abstract}
Hydrothermal liquefaction (HTL) of wet organic waste is a promising technology for producing renewable liquid fuels. However, implementation of the process at commercial scales must overcome several challenges. Efficient management of the contaminated aqueous phase generated after the conversion is necessary to limit water treatment expenses. In this study, we suggest the direct recycling of the aqueous phase at the inlet of the HTL process. The purpose is to evaluate the effect of recycling the process water on the bio-oil recovery and quality. HTL of blackcurrant pomace was performed in a batch autoclave, at a temperature of $310{ }^{\circ} \mathrm{C}$, with a holding time of $10 \mathrm{~min}$, and a dry biomass concentration of 14.5 wt \%. The influence of recycling the process water at the inlet of the process was evaluated for five recycle rounds. Recycling the process water has a positive effect on the bio-oil recovery, with the bio-oil yield increasing from $26 \mathrm{wt} \%$ to $31 \mathrm{wt} \%$ after five recycles. The energy recovery respectively increased from $48 \%$ to $57 \%$, mainly because of the better bio-oil yield. Along the recycling experiments, the aspect of the raw organic residue recovered from the reactor changed, from an oily solid to a free-flowing organic residue. Analytical results (total organic carbon, thermogravimetric analysis, and gas chromatography-mass spectroscopy (GC-MS) analysis) suggest that the improvement of the bio-oil yield is mainly due to the saturation of the aqueous phase with light-polar organics, which contribute to bio-oil formation by condensation reactions. Especially, products from the Maillard reaction could play an important role.
\end{abstract}

\section{INTRODUCTION}

Energy valorization of biomass through hydrothermal processes has received significant and increasing attention in recent years, to convert wet resources into energy-dense products in the form of solid, liquid, or gaseous fuels. ${ }^{1-3}$ Hydrothermal processes take advantage of the evolution of water properties in the subcritical and supercritical regions to degrade biomass. ${ }^{4}$ In particular, under subcritical conditions, liquid fuels can directly be produced from wet biomass via the hydrothermal liquefaction (HTL) process (temperature, $T=250-370{ }^{\circ} \mathrm{C}$; pressure, $P=10-30 \mathrm{MPa}$ ). The HTL process uses water as both a reaction medium and a reactant, avoiding the need to dry the resource before processing it. Through hydrothermal liquefaction, biomass is converted to four streams: (i) a biocrude or bio-oil with higher heating values up to 35-40 MJ $\mathrm{kg}^{-1}$, (ii) an aqueous phase containing light polar platform chemicals, (iii) a solid residue referred to as "char", and (iv) a $\mathrm{CO}_{2}$-rich gaseous phase. Hydrothermal liquefaction has been applied to a wide range of resources from wood ${ }^{5}$ to algae ${ }^{6}$ and food processing residues. ${ }^{7}$ The latter are of particular interest for valorization through hydrothermal liquefaction, because they are often wet resources, containing more than 50 wt \% water. They also contain a significant amount of valuable organic matter recovered either by extraction or separation processes $^{8,9}$ or by producing bio-based fuels. ${ }^{7}$ Food processing residues are generated in large and increasing amounts every year, leading to environmental, socio-economic, and sanitary problems. ${ }^{10,11}$ Therefore, efficient management and valor- ization of food processing wastes are required. Fruit residues are particularly relevant for valorization, since the fruit processing industry generates up to $50 \mathrm{wt} \%$ waste each year along the food supply chain. ${ }^{12}$

While HTL has been extensively studied at the laboratory scale for screening operating conditions and resources, commercial-scale implementation of the technology is being delayed by unresolved challenges. Some are relative to the valorization of the various streams generated along with the bio-oil. Because of the use of water as the reaction medium, the HTL process produces a non-negligible amount of contaminated water as a co-product, leading to large water handling requirements. In a continuous process, a certain level of purge is necessary to evacuate minerals. However, this purge causes also the loss of organic molecules that can eventually contribute to bio-oil production. The aqueous effluent is loaded with water-soluble organics and nutrients (salts), depending on the initial resource. Management of the aqueous effluent is a crucial point to consider for the economics of the process, because treatment in a sewage plant is expensive and may impair the financial advantages of HTL. Therefore, it is necessary to set up ways of recovering or recycling the organic load and nutrients contained in the wastewaters. This issue has recently received some attention, and several solutions have been suggested, such 
as catalytic hydrothermal gasification ( $\mathrm{CHG}$ ) to produce fuel gas, along with a relatively clean and nutrient-rich aqueous phase, ${ }^{13}$ direct recycling toward algae cultivation facilities, ${ }^{14,15}$ or anaerobic digestion. ${ }^{16-18}$ Attempts to recycle the entire reactor effluent at the inlet of the reactor led to the buildup of heavy products and highly viscous reaction medium, reducing the effectiveness of the process. ${ }^{19}$ Finally, few studies report the direct recycling of the aqueous phase at the inlet of the conversion unit. $3,5,20-22$ This solution appears to be the simplest and most economical option to deal with the aqueous stream, because it does not require any post-conversion treatment. In addition, recycling the process water to perform the conversion could reduce fresh water consumption and wastewater treatment requirements. Avoiding the consumption of additional fresh water could be highly beneficial for substrates requiring dilution before entering the process.

Some previous studies report the recycling of the process water into the HTL process itself. A group from the Pacific Northwest National Laboratory (USA) observed an improvement of the bio-oil yield and quality when recycling the aqueous phase from HTL of loblolly pine and corn stover. ${ }^{3} \mathrm{Li}$ et $\mathrm{al}^{20}$ reported increases of the bio-oil yield from $30.3 \%$ to $46.9 \%$ after recycling the process water three times during HTL of Salix psammophila. Zhu et al. ${ }^{21}$ reported increases of the biooil yield from $34.9 \mathrm{wt} \%$ to $38.4 \mathrm{wt} \%$ and heating value from 27.29 $\mathrm{MJ} \mathrm{kg}^{-1}$ to $28.4-29.4 \mathrm{MJ} \mathrm{kg}^{-1}$ after three recycle rounds of the aqueous phase produced by HTL of barley straw at 300 ${ }^{\circ} \mathrm{C}$ and a holding time of $15 \mathrm{~min}$. Solid residues were, at the same time, obtained in higher amounts. Ramos-Tercero et al. ${ }^{22}$ reported an $\sim 3$-fold increase of the bio-oil yield, from 14.3 wt $\%$ to 42.2 wt $\%$ after seven cycles during HTL of the microalgae Chlorella vulgaris at $240^{\circ} \mathrm{C}$ and a holding time of 30 min. Finally, Pedersen et al. ${ }^{5}$ tested the aqueous phase recirculation during continuous hydrothermal coliquefaction of aspen wood and glycerol in supercritical water $\left(400{ }^{\circ} \mathrm{C}, 300\right.$ bar). Even though experimental issues prevented them from identifying a clear tendency on bio-oil yields, they observed a better bio-oil quality as well as accumulation of total organic carbon (TOC) and ash in the water phase. According to the few previous studies on the subject, the influence of process water recycle and the associated mechanisms are still unclear.

The objective of the present paper is to study the influence of recycling the aqueous phase on hydrothermal liquefaction of fruit processing residues, using blackcurrant pomace as a reference biomass. This resource is representative of fibrous residues recovered after fruit pressing, mainly constituted by seeds, peels, and pulp. In this study, we report a series of batch experiments on blackcurrant pomace with recirculation of the aqueous phase. We focus on the bio-oil recovery, and report analytical data and properties of the bio-oil, to evaluate the effect of recycling the aqueous phase on its quality.

\section{MATERIALS AND METHODS}

2.1. Materials. The experiments were performed using blackcurrant (Ribes nigrum L.) pomace supplied by Les Vergers Boiron, who is a local producer of fruit purees and coulis operating in Valence, France. Blackcurrant pomace is the press cake recovered after juice production by berry pressing of two mixed cultivars, namely, Noir de Bourgogne and Andega. It is mainly constituted by seeds, peels, and pulp: it is a wet and fiber-rich biomass, also containing a non-negligible amount of proteins and some lipids. Detailed analysis of the biomass is reported in Table 1. For the first run of HTL before recycling
Table 1. Characterization of Blackcurrant Pomace

\begin{tabular}{lcc} 
& $\begin{array}{c}\text { blackcurrant } \\
\text { pomace }\end{array}$ & \multicolumn{1}{c}{ standard used } \\
$\begin{array}{l}\text { moisture content (wt \%) } \\
\text { fiber content (wt \% of dry } \\
\text { matter) }\end{array}$ & 59.6 & EN 14774-1 \\
neutral detergent fibers, & 61.7 & NF V18-122 \\
NDF & & NF V18-122 \\
acid detergent fibers, & 52.8 & NF V18-122 \\
ADF & 35.4 & Kjeldahl method \\
acid detergent lignin, & 16.9 & hydrochloric acid digestion + \\
ADL & & petroleum ether extraction \\
proteins (wt \% of dry \\
matter)
\end{tabular}

the aqueous phase, distilled water was used. Ethyl acetate used for bio-oil recovery was purchased from Sigma-Aldrich and used as received.

2.2. Hydrothermal Liquefaction. 2.2.1. Hydrothermal Liquefaction (HTL) Experiments. HTL experiments were performed in a $0.6 \mathrm{~L}$ stainless steel (type 316 ) stirred batch reactor (Parr Instruments). In the first run of the experiments, the reactor was filled with $\sim 240 \mathrm{~g}$ of biomass slurry prepared from raw blackcurrant pomace and distilled water. A constant concentration of 14.5 wt \% dry biomass in the reaction slurry was used, chosen based on previous experiments in our laboratory on the HTL of blackcurrant pomace. In subsequent runs, the biomass slurry was prepared from the aqueous phase recovered from the previous run, and the same amount of biomass as the first run. Figure 1 shows the experimental procedure for recycling experiments. The autoclave was leaktested, purged, and pressurized to $1 \mathrm{MPa}$ with nitrogen gas to guarantee sufficient pressure for gas analysis after the reaction. The total pressure inside the reactor was a function of the initial nitrogen pressure and the reaction temperature, as well as the amount of water and produced gas. Reaction conditions were selected from previous experiments in our laboratory on HTL of blackcurrant pomace that allowed high bio-oil yields. The reactor was heated from room temperature to the reaction temperature $\left(310{ }^{\circ} \mathrm{C}\right)$ within $\sim 35 \mathrm{~min}$. Once the reactor reached the reaction temperature, it was subjected to a holding time of 10 min within $\pm 1{ }^{\circ} \mathrm{C}$ of the reaction temperature, and stirred at $600 \mathrm{rpm}$. After the holding time, the reactor was rapidly cooled to room temperature in $20 \mathrm{~min}$ by an air quench. We show in Figure 2 typical operating conditions during an experiment. The gas in the reactor was vented and analyzed by a microchromatograph (Varian Quad CP 4900) used on line. Permanent gases $\left(\mathrm{O}_{2}, \mathrm{H}_{2}, \mathrm{CO}\right.$, and $\left.\mathrm{CH}_{4}\right)$ were analyzed by a molecular sieve column using argon as carrier gas. Light hydrocarbons $\left(\mathrm{C}_{2} \mathrm{H}_{4}, \mathrm{C}_{2} \mathrm{H}_{6}, \mathrm{C}_{2} \mathrm{H}_{2}\right.$, and $\left.\mathrm{C}_{3} \mathrm{H}_{8}\right), \mathrm{CO}_{2}$, and sulfur species $\left(\mathrm{H}_{2} \mathrm{~S}, \mathrm{COS}\right)$ were analyzed on a Poraplot- $\mathrm{U}$ column, using helium as the carrier gas. The quantity of gas formed 


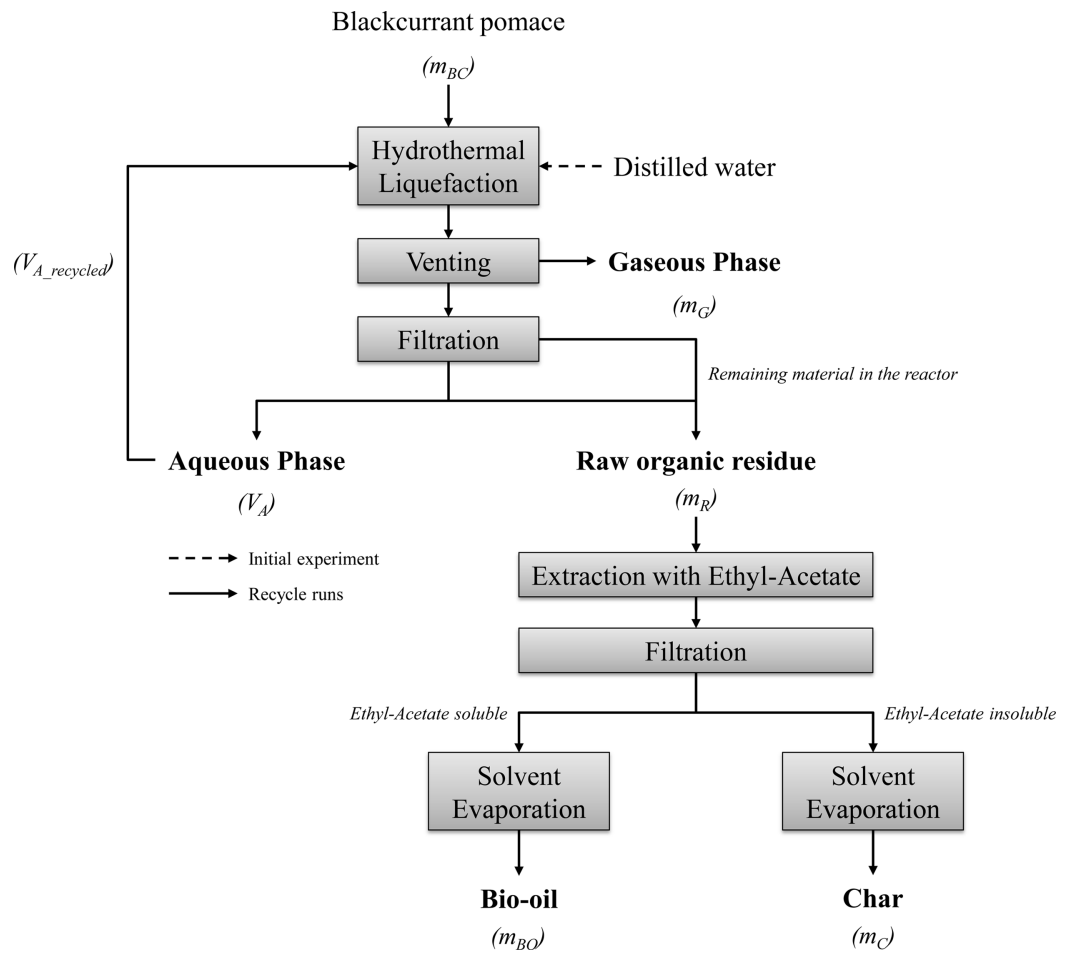

Figure 1. Experimental procedure for recycle experiments and recovery of products.

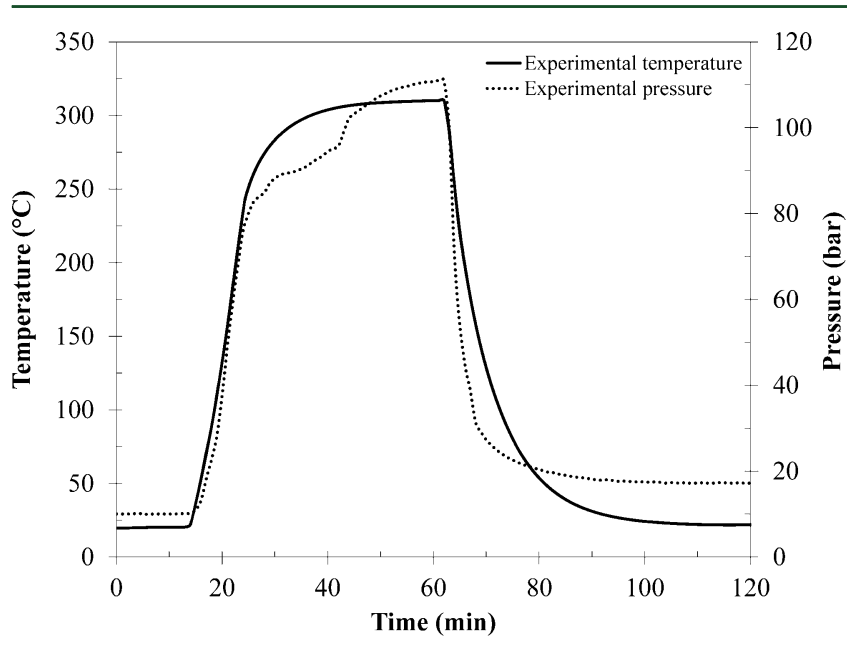

Figure 2. Temperature and pressure profiles during an experiment.

during the experiment was calculated by using the initial and final temperature and pressure measurements, using the ideal gas law, and the composition of the gas phase obtained by microchromatography. Solid and liquid products were then recovered and analyzed following the recovery procedure described in section 2.2.2.

2.2.2. Product Recovery Procedure. After gas analysis, the reactor was opened and the products were recovered, following the procedure given in Figure 1. The content of the reactor was first filtered on a Buchner filter to separate the aqueous phase from the raw organic residue. The raw organic residue was sticky and removed from the reactor as best as possible. The reactor was then weighed and the weight difference with the empty reactor was counted as remaining raw organic residue (wet). As shown in Figure 1, the material left in the reactor was taken into account to calculate the mass yields (section 3.1). The moisture content of the raw organic residue $\left(W_{\mathrm{R}}\right)$ was estimated using two methods: drying under air circulation until a stable mass was obtained, and Karl Fischer titration using a Schott Instruments Titroline KF. Combination of both methods allows one to evaluate the experimental error due to estimation of the moisture content of the raw organic residue. The difference is partly due to the evaporation of certain volatile compounds.

The raw organic residue was then extracted using a 10 -fold amount of ethyl acetate (w/w) to separate the bio-oil from the char on a Buchner filter. Ethyl acetate was chosen as extraction solvent, because it allows good bio-oil recovery, ${ }^{23}$ and has low toxicity and low miscibility with water. Bio-oil was recovered after evaporation of ethyl acetate at room temperature under air circulation until a stable mass was obtained. An estimation of the residual solvent amount in the bio-oil was performed by dissolving the bio-oil recovered after solvent evaporation in 2propanol, followed by GC-MS analysis. The analysis showed that only traces of ethyl acetate were left after evaporation. Thus, it was assumed that no significant amount of residual solvent was left in the bio-oil. The char was also dried at room temperature under air circulation until a stable mass was obtained. Weight loss of the char after extraction and drying was used to determine the proportion of solvent-soluble organics in the raw organic residue (SSO), and therefore the bio-oil yield $\left(Y_{\mathrm{BO}}\right)$. Calculations of the yields are explained in section 3.1.

2.2.3. Analyses of the Products. Total carbon content of the solid $\left(C_{\mathrm{C}}\right)$ and oil samples $\left(C_{\mathrm{BO}}\right)$ was quantified by a TOC analyzer (Shimadzu, Model SSM-5000A). Total carbon of the aqueous phase $\left(\mathrm{CT}_{\mathrm{A}}\right)$ was also quantified by a TOC analyzer (Shimadzu TOC-L CSH/CSN). Higher heating values of the solid and oil samples were measured using a Parr 6200 bomb calorimeter.

The molecular composition of the bio-oil was analyzed by a gas chromatography system that was coupled with a mass 
spectrometer, GC-MS (Clarus 500/Clarus 600S, PerkinElmer) equipped with a DB-1701 capillary column $60 \mathrm{~m} \times 0.25 \mathrm{~mm}$, $0.25 \mu \mathrm{m}$ film thickness. A $1 \mu \mathrm{L}$ sample was injected into the instrument with a split ratio of 10:1. Helium was used as carrier gas. The GC oven temperature was programmed from $45^{\circ} \mathrm{C}$ $(10 \mathrm{~min})$ to $230{ }^{\circ} \mathrm{C}$ at a rate of $6{ }^{\circ} \mathrm{C} \mathrm{min}{ }^{-1}$, and held at $230^{\circ} \mathrm{C}$ during $9.17 \mathrm{~min}$. It was then raised to $250{ }^{\circ} \mathrm{C}$ at a rate of $10^{\circ} \mathrm{C}$ $\min ^{-1}$, and held at $250{ }^{\circ} \mathrm{C}$ during $20 \mathrm{~min}$. The NIST mass spectral database was used to identify the peaks. For GC-MS analysis of bio-oils, a mass ratio of raw organic residue to ethyl acetate of $1: 1$ was used to minimize the effect of potential solvent pollution on the chromatograms. Organic molecules in the water phase were extracted with ethyl acetate and analyzed using the same procedure.

Thermogravimetric analysis (TGA) of the bio-oil was performed to evaluate the boiling-point distribution of the bio-oil and the fraction of bio-oil analyzed by GC-MS, using a Setaram Setsys Evolution apparatus. A sample of 5-6 mg biooil in a platinum crucible was heated from $60{ }^{\circ} \mathrm{C}$ to $900{ }^{\circ} \mathrm{C}$ at a rate of $10{ }^{\circ} \mathrm{C} \mathrm{min}{ }^{-1}$ to let it evaporate under a $50 \mathrm{~mL} \mathrm{~min}{ }^{-1}$ nitrogen flow. The boiling-point distribution was compared to the classification proposed by Speight for petroleum products. ${ }^{24}$ Here, the gas fraction (boiling points $<15^{\circ} \mathrm{C}$ ) is not applicable.

\section{CALCULATIONS}

3.1. Calculation of the Yields. Mass yields were calculated from the obtained experimental results. They are defined as the mass ratios between the products and the dry biomass used in the experiment. The bio-oil $\left(Y_{\mathrm{BO}}\right.$, eq 1$)$ and char $\left(\mathrm{Y}_{\mathrm{C}}\right.$, eq 2$)$ yields were calculated using the results from solvent extraction:

$$
\begin{aligned}
& Y_{\mathrm{BO}}=\frac{m_{\mathrm{BO}}}{m_{\mathrm{BC}}}=\frac{m_{\mathrm{R}} \cdot\left(\mathrm{SSO}-W_{\mathrm{R}}\right)}{m_{\mathrm{BC}}} \\
& Y_{\mathrm{C}}=\frac{m_{\mathrm{C}}}{m_{\mathrm{BC}}}=\frac{m_{\mathrm{R}} \cdot(1-\mathrm{SSO})}{m_{\mathrm{BC}}}
\end{aligned}
$$

where $Y_{\mathrm{BO}}$ is the bio-oil yield (wt \% of dry blackcurrant pomace), $Y_{\mathrm{C}}$ is the char yield (wt \% of dry blackcurrant pomace), $m_{\mathrm{BO}}$ is the mass of bio-oil ( $\left.\mathrm{g}\right), m_{\mathrm{BC}}$ is the mass of the dry blackcurrant pomace $(\mathrm{g}), m_{\mathrm{R}}$ is the mass of raw organic residue $(\mathrm{g}), m_{\mathrm{C}}$ is the mass of char $(\mathrm{g})$, SSO is the proportion of solvent-soluble organics (wt \%), and $W_{\mathrm{R}}$ is the water content of raw organic residue (wt \%).

The gas yield $\left(Y_{\mathrm{G}}\right.$, eq 4$)$ was calculated by initial and final temperature and pressure measurements using the ideal gas law, combined with the composition of the gas phase obtained by microchromatography (eq 3):

$$
\begin{aligned}
& m_{\mathrm{G}}=\frac{V_{\mathrm{G}}}{R} \cdot\left(\frac{P_{\mathrm{f}}}{T_{\mathrm{f}}}-\frac{P_{\mathrm{i}}}{T_{\mathrm{i}}}\right) \cdot \sum_{j} M_{j} \cdot y_{j} \\
& Y_{\mathrm{G}}=\frac{m_{\mathrm{G}}}{m_{\mathrm{BC}}}
\end{aligned}
$$

where $m_{\mathrm{G}}$ is the mass of gas $(\mathrm{g}), V_{\mathrm{G}}$ is the volume of gaseous phase in the reactor $\left(\mathrm{m}^{3}\right), R$ is the ideal gas constant $(R=8.314$ $\left.\mathrm{J} \mathrm{K}^{-1} \mathrm{~mol}^{-1}\right), P_{\mathrm{f}}$ is the final pressure in the reactor $(\mathrm{Pa}), P_{\mathrm{i}}$ is the initial pressure in the reactor $(\mathrm{Pa}), T_{\mathrm{f}}$ is the final temperature in the reactor $(\mathrm{K}), T_{\mathrm{i}}$ is the initial temperature in the reactor $(\mathrm{K})$, $M_{j}$ is the molar mass of gaseous species $j\left(\mathrm{~g} \mathrm{~mol}^{-1}\right), y_{j}$ is the molar fraction of gaseous species $j$, and $Y_{\mathrm{G}}$ is the gas yield (wt \% of dry blackcurrant pomace).
In practice, the quantity of organic matter in the water phase is difficult to assess by simple drying, because many compounds are volatile. In the literature, the aqueous phase yield is sometimes calculated by difference, closing the mass balance on the organic matter to $100 \% .^{25,26}$ By doing so, the aqueous phase yield integrates the mass balance closure error. Because of hydration and dehydration reactions, the overall organic mass balance does not necessarily close to $100 \%$. Therefore, we do not report the mass yield of organics in the aqueous phase, together with the mass yield of the other phases, since it cannot be accurately determined. However, carbon recovery in the aqueous phase can be determined and is reported as presented in section 3.2 .

3.2. Calculation of the Carbon Distribution. Carbon recoveries are defined as the ratios between the mass of carbon contained in the recovered phases and the initial mass of carbon before the reaction. It is necessary to separate the first run (no recycle) from the subsequent runs. Carbon recoveries in the bio-oil and char were calculated according to the following formulation (eqs 5-8):

First run:

$$
\begin{aligned}
& \mathrm{CR}_{\mathrm{BO}}=\frac{C_{\mathrm{BO}} \cdot m_{\mathrm{BO}}}{C_{\mathrm{BC}} \cdot m_{\mathrm{BC}}} \\
& \mathrm{CR}_{\mathrm{C}}=\frac{C_{\mathrm{C}} \cdot m_{\mathrm{C}}}{C_{\mathrm{BC}} \cdot m_{\mathrm{BC}}}
\end{aligned}
$$

Subsequent recycle runs:

$$
\begin{aligned}
\mathrm{CR}_{\mathrm{BO}} & =\frac{C_{\mathrm{BO}} \cdot m_{\mathrm{BO}}}{C_{\mathrm{BC}} \cdot m_{\mathrm{BC}}+\mathrm{CT}_{\mathrm{A} \_ \text {recycled }} \cdot V_{\mathrm{A} \_ \text {recycled }}} \\
\mathrm{CR}_{\mathrm{C}} & =\frac{C_{\mathrm{C}} \cdot m_{\mathrm{C}}}{C_{\mathrm{BC}} \cdot m_{\mathrm{BC}}+\mathrm{CT}_{\mathrm{A} \_ \text {recycled }} \cdot V_{\mathrm{A} \_ \text {recycled }}}
\end{aligned}
$$

where $\mathrm{CR}_{\mathrm{BO}}$ and $\mathrm{CR}_{\mathrm{C}}$ are the carbon recovery in bio-oil and in char (wt \% of initial carbon), respectively; $C_{\mathrm{BO}}, C_{\mathrm{BC}}$, and $C_{\mathrm{C}}$ are the carbon content in bio-oil, dry blackcurrant pomace, and char (wt \%), respectively; $m_{\mathrm{BO}}, m_{\mathrm{BC}}$, and $m_{\mathrm{C}}$ are the mass of bio-oil, dry blackcurrant pomace, and char $(\mathrm{g})$, respectively; $\mathrm{CT}_{\mathrm{A} \text { recycled }}$ is the concentration of total carbon in the recycled aqueous phase $\left(\mathrm{g} \mathrm{L}^{-1}\right)$; and $V_{\mathrm{A}-\text { recycled }}$ is the volume of recycled aqueous phase $(\mathrm{L})$.

The carbon recovery in the gaseous phase (eqs 9-11) was calculated from the composition of the gaseous phase obtained by microchromatography, as shown below:

$$
m(C)_{\mathrm{G}}=\frac{V_{\mathrm{G}}}{R} \cdot\left(\frac{P_{\mathrm{f}}}{T_{\mathrm{f}}}-\frac{P_{\mathrm{i}}}{T_{\mathrm{i}}}\right) \cdot M(C) \cdot \sum_{j} N_{\mathrm{C}_{j} j} \cdot y_{j}
$$

First run:

$$
\mathrm{CR}_{\mathrm{G}}=\frac{m(C)_{\mathrm{G}}}{C_{\mathrm{BC}} \cdot m_{\mathrm{BC}}}
$$

Subsequent recycle runs:

$$
\mathrm{CR}_{\mathrm{G}}=\frac{m(C)_{\mathrm{G}}}{C_{\mathrm{BC}} \cdot m_{\mathrm{BC}}+\mathrm{CT}_{\mathrm{A} \_ \text {recycled }} \cdot V_{\mathrm{A} \_ \text {recycled }}}
$$

where $m(C)_{\mathrm{G}}$ is the mass of carbon in gaseous phase $(\mathrm{g}) ; V_{\mathrm{G}}$ is the volume of gaseous phase in the reactor $\left(\mathrm{m}^{3}\right) ; R$ is the ideal gas constant $\left(R=8.314 \mathrm{~J} \mathrm{~K}^{-1} \mathrm{~mol}^{-1}\right)$; $P_{\mathrm{f}}$ is the final pressure in the reactor $(\mathrm{Pa}) ; P_{\mathrm{i}}$ is the initial pressure in the reactor $(\mathrm{Pa}) ; T_{\mathrm{f}}$ 
is the final temperature in the reactor $(\mathrm{K}) ; T_{\mathrm{i}}$ is the initial temperature in the reactor $(\mathrm{K}) ; M(C)$ is the molar mass of carbon $\left(\mathrm{g} \mathrm{mol}^{-1}\right) ; N_{\mathrm{C}}$ is the number of carbon atoms in gaseous species $j ; y_{j}$ is the molar fraction of gaseous species $j$; $\mathrm{CR}_{\mathrm{G}}$ is the carbon recovery in gas (wt \% of initial carbon); $C_{\mathrm{BC}}$ is the carbon content in dry blackcurrant pomace (wt \%); $m_{\mathrm{BC}}$ is the mass of dry blackcurrant pomace $(\mathrm{g}) ; \mathrm{CT}_{\mathrm{A} \text { recycled }}$ is the concentration of total carbon in the recycled aqueous phase ( $\mathrm{g}$ $\left.\mathrm{L}^{-1}\right)$; and $V_{\mathrm{A}-\text { recycled }}$ is the volume of recycled aqueous phase (L).

Finally, the carbon recovery in the aqueous phase was calculated according to the following formulation (eqs 12 and 13):

First run:

$$
\mathrm{CR}_{\mathrm{A}}=\frac{V_{\mathrm{A}} \cdot \mathrm{CT}_{\mathrm{A}}}{C_{\mathrm{BC}} \cdot m_{\mathrm{BC}}}
$$

Subsequent recycle runs:

$$
\mathrm{CR}_{\mathrm{A}}=\frac{V_{\mathrm{A}} \cdot \mathrm{CT}_{\mathrm{A}}}{C_{\mathrm{BC}} \cdot m_{\mathrm{BC}}+\mathrm{CT}_{\mathrm{A} \_ \text {recycled }} \cdot V_{\mathrm{A} \_ \text {recycled }}}
$$

where $\mathrm{CR}_{\mathrm{A}}$ is the carbon recovery in aqueous phase (wt \% of initial carbon); $V_{\mathrm{A}}$ is the volume of aqueous phase (L); $\mathrm{CT}_{\mathrm{A}}$ is the concentration of total carbon in aqueous phase $\left(\mathrm{g} \mathrm{L}^{-1}\right) ; C_{\mathrm{BC}}$ is the carbon content in dry blackcurrant pomace (wt \%); $m_{\mathrm{BC}}$ is the mass of dry blackcurrant pomace $(\mathrm{g}) ; \mathrm{CT}_{\mathrm{A} \text { recycled }}$ is the concentration of total carbon in the recycled aqueous phase ( $\mathrm{g}$ $\left.\mathrm{L}^{-1}\right)$; and $V_{\mathrm{A}_{-} \text {recycled }}$ is the volume of recycled aqueous phase (L).

In the Results and Discussion section, experimental values are the mean values of two replicates of each experiment. Error bars represent the standard deviation.

3.3. Energy Recovery. The energy recovery ratio in the bio-oil $\left(\mathrm{ER}_{\mathrm{BO}}\right)$ from the blackcurrant pomace is defined as follows:

$$
\mathrm{ER}_{\mathrm{BO}}=\frac{m_{\mathrm{BO}} \cdot \mathrm{HHV}_{\mathrm{BO}}}{m_{\mathrm{BC}} \cdot \mathrm{HHV}_{\mathrm{BC}}}
$$

where $\mathrm{ER}_{\mathrm{BO}}$ is the energy recovery ratio in the bio-oil (\%); $m_{\mathrm{BO}}$ and $m_{\mathrm{BC}}$ are the mass of bio-oil and dry blackcurrant pomace $(\mathrm{g})$, respectively; $\mathrm{HHV}_{\mathrm{BO}}$ and $\mathrm{HHV}_{\mathrm{BC}}$ are the higher heating values of the bio-oil and dry blackcurrant pomace $\left(\mathrm{MJ} \mathrm{kg}{ }^{-1}\right)$, respectively.

In the above equation, the external energy input (electricity) necessary to achieve and maintain reaction conditions is not taken into account.

\section{RESULTS AND DISCUSSION}

In this section, we report the effect of recycling the aqueous phase on the recovery and quality of products. Operating conditions were as follows: a temperature of $310^{\circ} \mathrm{C}$, a holding time of $10 \mathrm{~min}$, and a dry biomass concentration of $14.5 \mathrm{wt} \%$ in the reaction slurry. The influence of recycling the aqueous phase was evaluated for six experiments. Experiments are labeled from $R_{0}$ (first run, no recycle) to $R_{5}$ (fifth recycle).

4.1. Influence of Recycling the Process Water on the Recovery of Products. Figure 3 shows the effect of recycling the aqueous phase on the yields and carbon distribution between products. Results of the experiments show that the bio-oil yield has a tendency to increase along the experiments, from $26 \mathrm{wt} \%$ in the first run to almost $31 \mathrm{wt} \%$ in the last recycles. A decrease in the char yield, from $35 \mathrm{wt} \%$ to $32 \mathrm{wt} \%$,
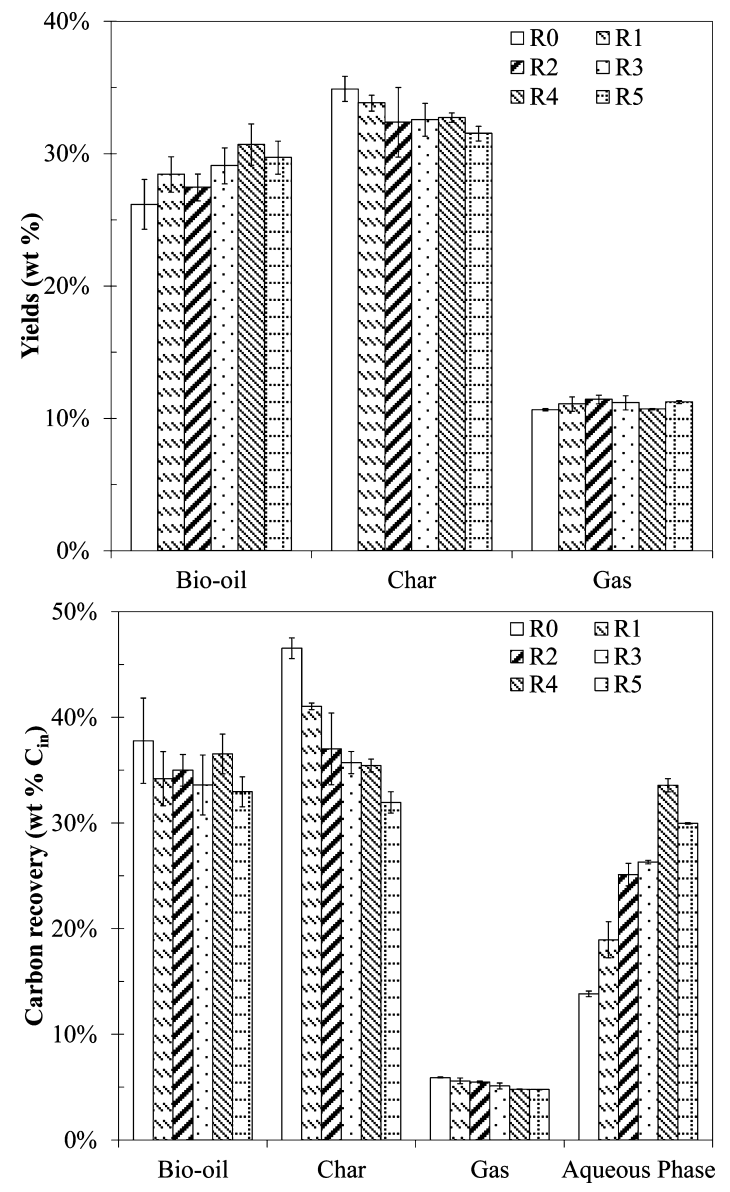

Figure 3. Effect of recycling the aqueous phase on products distribution and carbon recovery $\left(R_{0}\right.$, no recycle; $R_{5}$, fifth recycle).

also is observed, while the gas yield is only slightly impacted. Overall, the mass ratio between the bio-oil and the char increases from 0.74 in experiment $R_{0}$ to 0.94 in experiment $R_{5}$ (see Figure 4). This is illustrated by the evolution of the aspect

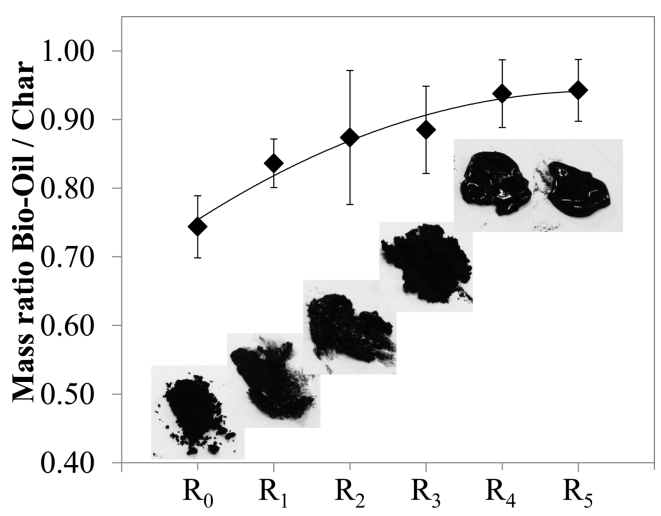

Figure 4. Evolution of the mass ratio bio-oil/char and evolution of the raw organic residue from runs $R_{0}-R_{5}\left(R_{0}\right.$, no recycle; $R_{5}$, fifth recycle).

of the raw organic residue along the recycle experiments. As can be seen from Figure 4, it changes from an oily solid to a freeflowing hydrophobic residue after several recycles. This suggests that the bio-oil could be recovered in a solvent-free process, because of the beneficial effect of recycling the aqueous phase. Global mass balances and carbon balances vary from 
99.6 wt \% to 110.3 wt \% for this set of experiments, which is relatively good, considering the experimental error.

Table 2 shows the effect of recycling the aqueous phase on the HHV of the bio-oils for each run, and the corresponding

Table 2. Evolution of Higher Heating Value of the Bio-oil and Energy Recovery in the Bio-oil along the Recycle Experiments

$\begin{array}{crc}\text { number of recycles } & \mathrm{HHV}_{\mathrm{BO}}\left(\mathrm{MJ} \mathrm{kg}^{-1}\right) & \mathrm{ER}_{\mathrm{BO}}(\%) \\ 0 \text { (first run) } & 33.0( \pm 2.4) & 48( \pm 6) \\ 1 & 32.0( \pm 2.9) & 48( \pm 3) \\ 2 & 34.8( \pm 0.3) & 52( \pm 2) \\ 3 & 34.5( \pm 0.8) & 54( \pm 3) \\ 4 & 35.2( \pm 0.5) & 58( \pm 3) \\ 5 & 35.2( \pm 0.6) & 57( \pm 2)\end{array}$

energy recovery. A slight increase of the HHV is observed along the recycle experiments from $32-33 \mathrm{MJ} \mathrm{kg}^{-1}$ to $35-36 \mathrm{MJ}$ $\mathrm{kg}^{-1}$, corresponding to an increased energy recovery in the biooil from $48 \%$ to $57 \%$, mainly linked to a better bio-oil yield. This is consistent with other published studies on the effect of recycling the process water. For instance, $\mathrm{Zhu}$ et al. ${ }^{21}$ reported increased $\mathrm{HHV}$ of the bio-oil from 27.29 $\mathrm{MJ} \mathrm{kg}^{-1}$ to $28.4-29.4$ $\mathrm{MJ} \mathrm{kg}$ after three recycle rounds of the aqueous phase produced by the HTL of barley straw at $300{ }^{\circ} \mathrm{C}$ and a holding time of $15 \mathrm{~min}$. Ramos-Tercero et al. ${ }^{22}$ observed increased energy recoveries in the bio-oil, from $25 \%$ to $68 \%$ after recycling the aqueous phase six times during HTL of the microalgae $C$. vulgaris at $240{ }^{\circ} \mathrm{C}$ and a holding time of $30 \mathrm{~min}$.

4.2. Evolution of the Aqueous Phase along the Recycling Experiments. 4.2.1. Evolution of the Organic Load of the Aqueous Phase. Along the experiments, the color of the aqueous phase recovered changed from light yellow to strong orange/brown, suggesting the enrichment of the aqueous phase by organic compounds. When considering the carbon distribution between phases, we observe that the carbon recovery in the aqueous phase increases from one experiment to the following: the aqueous phase gets enriched in watersoluble organics, as shown in Figure 5. The total organic carbon (TOC) concentration of the aqueous phase actually reaches a plateau at $\sim 35 \mathrm{~g} \mathrm{~L}^{-1}$ after several recycle experiments. This is consistent with other studies reported in the literature,

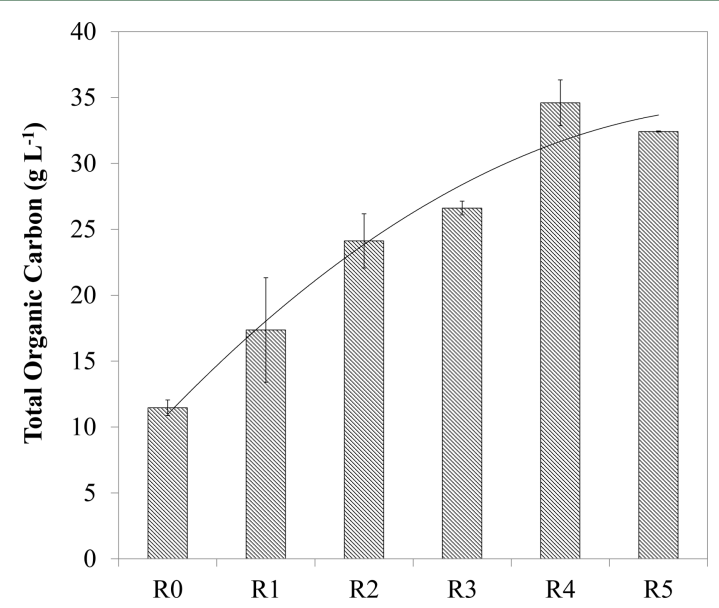

Figure 5. Evolution of total organic carbon (TOC, $\mathrm{g} \mathrm{L}^{-1}$ ) in the aqueous phase along the recycle experiments $\left(R_{0}\right.$, no recycle; $R_{5}$, fifth recycle). suggesting that the increase of the bio-oil yield is due to the saturation of the aqueous phase with light-polar organics. ${ }^{5,22} \mathrm{~A}$ clear decrease of the carbon recovery is observed in the char, from 47 wt \% to 32 wt \%, because carbon accumulates in the aqueous phase (Figure 3). The saturation of the aqueous phase could drive bio-oil formation by condensation of water-soluble intermediates, as we discuss in the following sections. However, it could also lead ultimately to bad separation of the bio-oil from the aqueous phase, as observed by Pedersen et al. ${ }^{5}$

4.2.2. Gas Chromatography-Mass Spectroscopy (GC-MS) Analysis of the Aqueous Phase. Figure 6 shows the

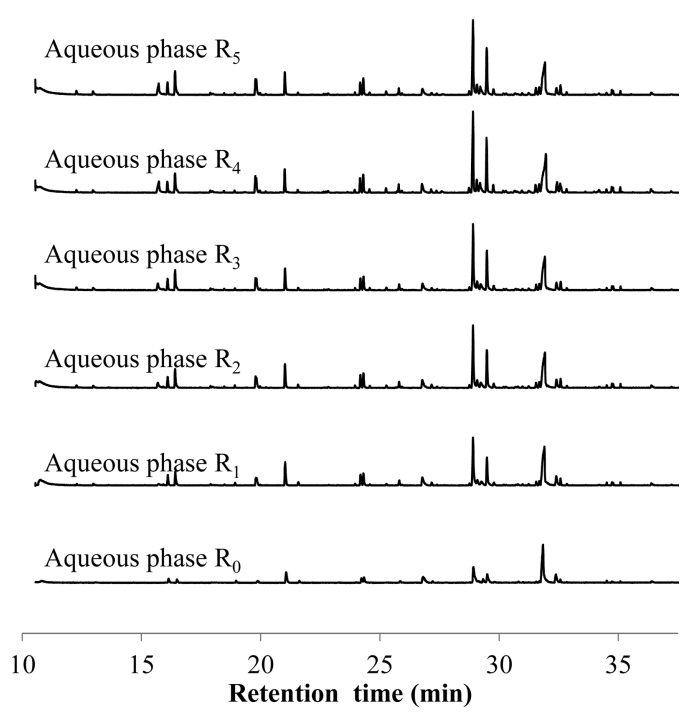

Figure 6. GC-MS analyses of the aqueous phases recovered from recycle runs $\left(\mathrm{R}_{0}\right.$, no recycle; $\mathrm{R}_{5}$, fifth recycle).

chromatograms obtained by GC-MS analysis of the aqueous phases recovered from the recycle runs. Although we did not quantify the compounds, some changes can be noticed along the experiments, when considering relative peak areas. Detailed analysis is given in Table S1 in the Supporting Information. Note that only the compounds with relative peak areas of $>1 \%$ of the total area in experiment $\mathrm{R}_{5}$ are referenced: they represent $83.1 \%$ (experiment $\mathrm{R}_{0}$ ) to $87.6 \%$ (experiment $\mathrm{R}_{5}$ ) of the total area.

The aqueous phase is composed of numerous molecules: carboxylic acids, cyclic ketones, nitrogenous heterocycles, and phenol derivatives. Acetic acid has previously been designated as an influential compound to explain the improvement of biooil yields, although its influence is not clear. ${ }^{20,22}$ GC-MS analysis of the aqueous phases shows that the relative peak area of acetic acid is only slightly affected, compared to other species, especially when considering the evolution of nitrogenous heterocycles. Rather than the sole acetic acid, our results have a tendency to confirm those reported by RamosTercero et al., ${ }^{22}$ who suggested that the entire organic load of the aqueous phase contributes to increase the bio-oil yield. The role of acetic acid is most likely dependent on the biochemical composition of the initial biomass and especially on the nature and amount of fibers.

GC-MS analysis of the aqueous phases shows increases of the relative peak areas of many compounds along the recycle experiments, with a diversification of reaction products. This indicates possible changes in reaction pathways. The light-polar organics contained in the aqueous phase could polymerize to 
heavier structures, increasing the bio-oil yield. The formation of bio-oil from the aqueous phase has recently been directly observed in situ by Cheng et al., ${ }^{27}$ using a microfluidic platform combined with fluorescence and dark-field imaging. We give more detailed information on the composition of bio-oils in section 4.3, which further supports this hypothesis.

Relative peak areas of nitrogenous heterocycles are particularly affected when the aqueous phase is recycled. For instance, the relative peak area of 3-pyridinol (retention time $=$ $31.9 \mathrm{~min}$ ) decreases from $26.1 \%$ in the $\mathrm{R}_{0}$ experiment to $14.6 \%$ in the $R_{5}$ experiment. At the same time, the relative peak areas of many compounds increase between experiments $R_{0}$ and $R_{5}$ (for instance, pyrazine derivatives (16.4 and $19.8 \mathrm{~min}$ ), or triazinedione derivative $(29.4 \mathrm{~min}))$. These compounds are mainly nitrogenous heterocycles, originating from interaction reactions between sugar and protein derivatives known as Maillard-type reactions. Minowa et al. ${ }^{28}$ observed that Maillard products could inhibit the degradation of the bio-oil to produce char. They postulated an inhibiting effect of $\mathrm{NH}_{3}$, which is produced by deamination reactions of the melanoidins (Maillard polymers) and water-soluble nitrogenous molecules. Maillard products act as scavengers of reactive intermediates, stopping degradation and polymerization pathways that lead to char and gas. ${ }^{29,30}$ The decrease of the char yield can then be linked to Maillard reactions occurring in the reaction medium, because of inhibition of the bio-oil degradation and less important polymerization pathways.

4.3. Evolution of the Bio-oil along the Recycling Experiments. In this section, we report the results of thermogravimetric analysis (TGA), which has been used in other published studies on aqueous phase recirculation ${ }^{20,21}$ to estimate the boiling-point distribution of bio-oils produced by hydrothermal liquefaction. Because of the limited amount of bio-oil samples, we could not perform a full distillation, but TGA is useful to obtain a rough estimate of the thermal behavior of the bio-oils. We report the results of GC-MS analysis of the light fraction of the bio-oil (boiling points $<250$ ${ }^{\circ} \mathrm{C}$ ) in section 4.3.2.

4.3.1. Thermogravimetric Analysis of the Bio-oil. Thermogravimetric analysis was conducted to evaluate the boilingpoint distribution of the bio-oils produced along the recycle experiments. Results of the analysis are reported in Figures 7 and 8 . The boiling-point distribution was evaluated according to the classification proposed by Speight for petroleum products. ${ }^{24}$ Results show that the bio-oils have globally the same evaporation behavior, which is consistent with other reported studies. ${ }^{20,21}$ The boiling-point distribution of bio-oils is mostly characterized by a medium naphtha fraction and highboiling constituents. However, some changes can be observed along the recycle experiments. Especially, the light naphtha fraction of the bio-oils has increased from $4.7 \pm 0.1 \mathrm{wt} \%$ to 7.6 $\pm 0.2 \mathrm{wt} \%$ of the bio-oil from experiment $R_{0}$ to experiment $R_{5}$, while heavier fractions have been decreased (boiling points over $371^{\circ} \mathrm{C}$ ). This means that the bio-oils have been enriched in lighter compounds with the increasing number of process water recycles. This was also reported by Ramos-Tercero et al., ${ }^{22}$ who observed a decrease in the average molecular mass of the bio-oil produced by HTL of $C$. vulgaris with the increasing number of recycles. The bio-oils are enriched in lighter compounds originating from the aqueous phase, such as small nitrogenous molecules. ${ }^{22}$ Our results have a tendency to confirm their observations, as we further discuss in section 4.3.2. Increasing the volatility of bio-oils might be interesting, because it would
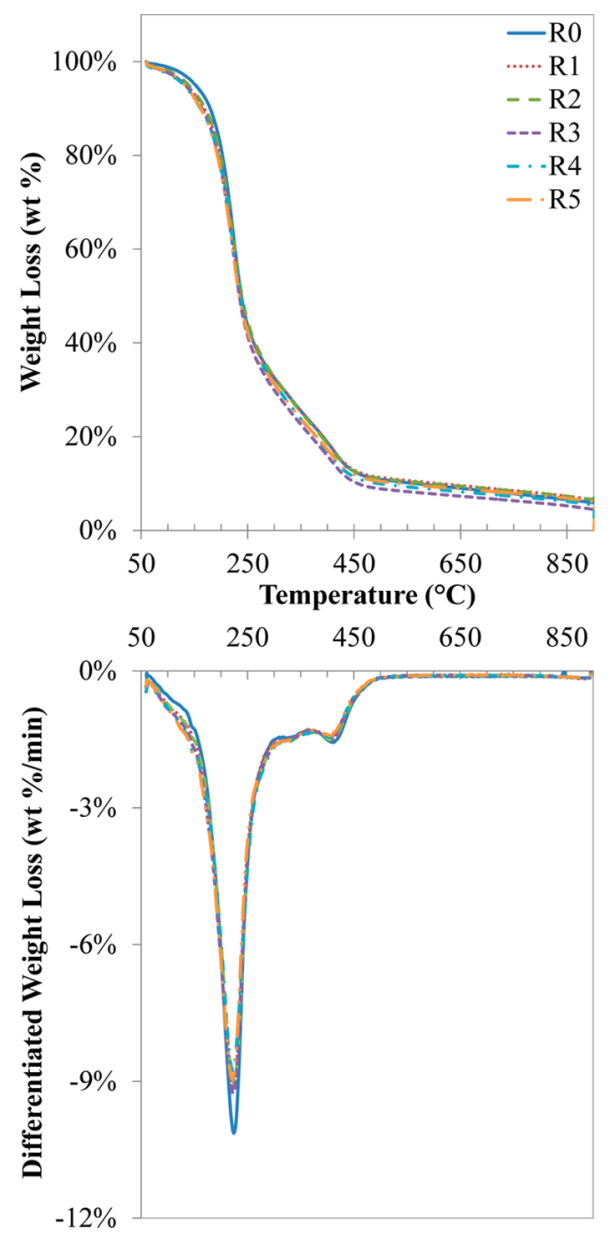

Figure 7. Thermogravimetric analysis of the bio-oils produced along the recycle experiments $\left(R_{0}\right.$, no recycle; $R_{5}$, fifth recycle).

reduce the heating needs for further upgrading steps or other applications. Yet, it could also lead to higher amounts of heteroatoms in the bio-oils and then higher upgrading needs. However, elemental analysis of the bio-oils shows the relative stability of the global composition of the bio-oils in the case of our study, as we report in Table 3. The bio-oils are relatively rich in oxygen and nitrogen, and should therefore be upgraded before any use as fuels.

4.3.2. GC-MS Analysis of the Bio-oil. GC-MS analysis was conducted on bio-oils before evaporation of ethyl acetate, to avoid the loss of volatile components upon evaporation of the extraction solvent. GC-MS analysis allows analysis of the volatile fraction of the bio-oil, up to $250{ }^{\circ} \mathrm{C}$. Therefore, it only provides partial information: from the TG analysis, we evaluated that $\sim 57 \mathrm{wt} \%$ of the total bio-oil is analyzed by GC-MS. The remaining fraction corresponds to high-boiling point molecules, and should be analyzed by other techniques adapted to nonvolatile compounds (e.g., liquid chromatography coupled with mass spectrometry).

Figure 9 shows the chromatograms obtained by GC-MS analysis of the bio-oils recovered from the recycle runs. The chromatograms show the highly complex chemical composition of the bio-oil, which is formed by hundreds to thousands of different structures. ${ }^{31}$ In Figure 9, it is noticeable that the chemical composition of the volatile fraction of the bio-oil is getting more complex when the aqueous phase is recycled. Especially, more compounds are detected at retention times 

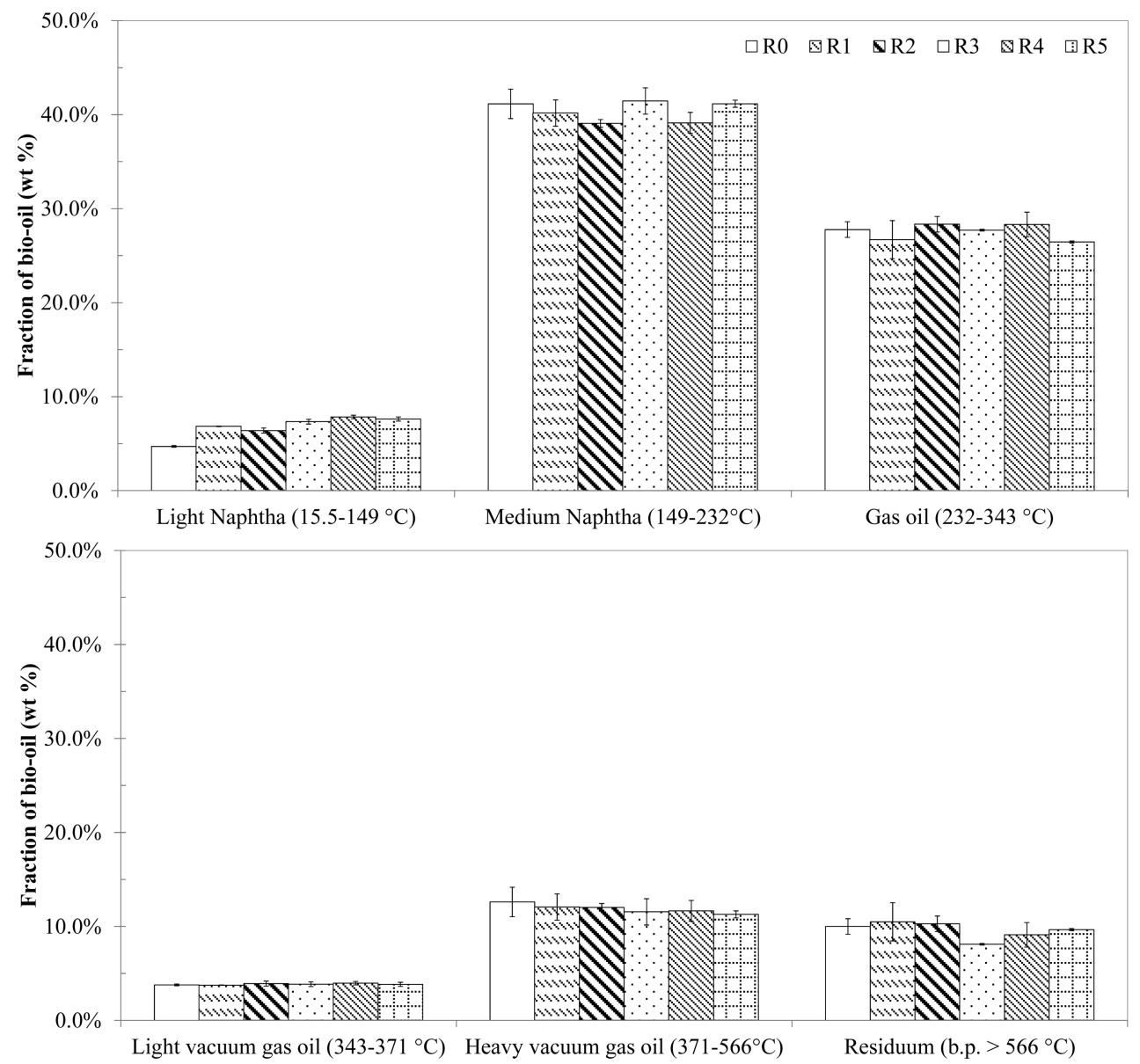

Figure 8. Boiling-point distribution of the bio-oils along the recycle experiments obtained by TGA ( $R_{0}$, no recycle; $R_{5}$, fifth recycle).

Table 3. Elemental Analysis of the Bio-oils Recovered from Experimental Runs $\mathbf{R}_{\mathbf{0}}-\mathbf{R}_{\mathbf{5}}$

\begin{tabular}{|c|c|c|c|c|c|}
\hline number of recycles & $\mathrm{C}(\mathrm{wt} \%)$ & $\mathrm{H}(\mathrm{wt} \%)$ & $\mathrm{N}($ wt \%) & $\mathrm{S}(\mathrm{wt} \%)$ & O (wt \%, by difference) \\
\hline 0 (first run) & $71.5 \pm 2.6$ & $9.8 \pm 0.4$ & $3.0 \pm 0.6$ & $0.1 \pm 0.0$ & $15.6 \pm 3.6$ \\
\hline 1 & $67.5 \pm 6.3$ & $9.8 \pm 0.4$ & $3.2 \pm 0.5$ & $0.1 \pm 0.0$ & $19.4 \pm 7.3$ \\
\hline 2 & $72.3 \pm 0.4$ & $9.6 \pm 0.3$ & $3.3 \pm 0.3$ & $0.2 \pm 0.0$ & $14.6 \pm 1.1$ \\
\hline 3 & $71.6 \pm 0.7$ & $9.6 \pm 0.2$ & $3.3 \pm 0.4$ & $0.2 \pm 0.1$ & $15.3 \pm 1.4$ \\
\hline 4 & $72.3 \pm 0.4$ & $9.6 \pm 0.2$ & $3.2 \pm 0.2$ & $0.2 \pm 0.0$ & $14.7 \pm 0.9$ \\
\hline 5 & $72.9 \pm 0.7$ & $9.8 \pm 0.1$ & $3.4 \pm 0.6$ & $0.2 \pm 0.0$ & $13.6 \pm 1.4$ \\
\hline
\end{tabular}

lower than $40 \mathrm{~min}$. This means that the bio-oil is enriched in light molecules along the recycle runs.

The presence of many coeluting peaks and similar structure identifications for different retention times by the mass spectral database makes exhaustive identification of the bio-oil composition difficult. Even though GC-MS analysis is limited by the complex composition of the mixture, an attempt to identify the main molecules is given in Table S2 in the Supporting Information. It gives a nonexhaustive overview of the evolution of relative peak areas. Note that only the compounds with relative peak areas of $>1 \%$ of the total area in experiment $R_{5}$ are referenced: they represent $27.0 \%$ (experiment $R_{0}$ ) to $83.5 \%$ (experiment $R_{5}$ ) of the total area, showing the enrichment of the bio-oil in light molecules along the recycle runs.

As it was the case with aqueous phases, some changes can be noticed along the recycle experiments, when considering relative peak areas. From GC-MS analyses of the bio-oils, we can see that the bio-oils have been enriched in light molecules.
In fact, relative peak areas increase for the majority of the detected compounds. This confirms our TG analyses, where we observed lighter fractions in the bio-oil after several recycling steps of the aqueous phases. As well, it has a tendency to confirm results reported by Ramos-Tercero et al., ${ }^{22}$ who observed an enrichment of the bio-oil in lighter compounds after recycle experiments. This is due to the saturation of the aqueous phase with light polar organics, which favor the condensation of water-soluble organics to form bio-oil. ${ }^{27}$ In addition, we see that the relative peak areas of fatty acids derivatives (e.g., long-chain amides) significantly increase when the aqueous phase is recycled as the reaction solvent. These compounds have amphiphilic properties, because of their hydrophobic long-chain associated with a polar group at one end of the hydrophobic chain. The stabilization of this type of compounds when recycling the aqueous phase could change the interfacial properties of the bio-oil, which might also explain the evolution of the aspect of the raw organic residue shown in Figure 4. The raw organic residue changes from an oily and 


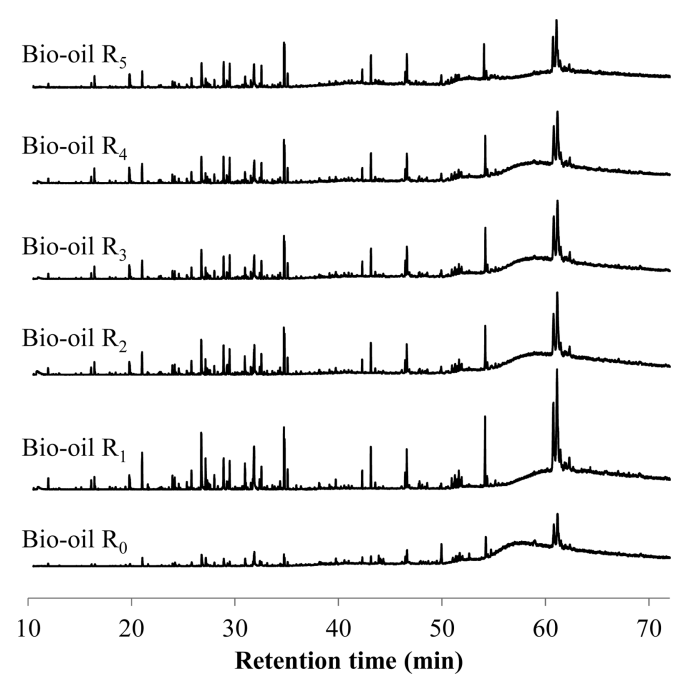

Figure 9. GC-MS analyses of the bio-oils recovered from recycle runs $\left(\mathrm{R}_{0}\right.$, no recycle; $\mathrm{R}_{5}$, fifth recycle).

relatively polar solid to a more hydrophobic heavy oil, the surface of which may be formed of polar groups attached to long hydrophobic chains.

\section{CONCLUSION}

In this paper, we have described the effect of recycling the process water in the reaction medium on hydrothermal liquefaction (HTL) of blackcurrant pomace. Operating conditions were a temperature of $310^{\circ} \mathrm{C}$, a holding time of $10 \mathrm{~min}$, and a dry biomass concentration of $14.5 \mathrm{wt} \%$ in the reaction slurry. Recycling the process water has a positive effect on hydrothermal liquefaction of blackcurrant pomace. Results of six consecutive experiments show that recycling the aqueous phase seems to benefit to the bio-oil yield, which is enhanced from 26 wt \% to 31 wt \%. A slight improvement of the higher heating values of the bio-oils is also observed. The overall energy recovery in the bio-oil increases from $48 \%$ to $57 \%$, mainly due to the higher bio-oil and lower char yields. Analytical results suggest that the enhancement of bio-oil yield is mainly due to the saturation of the aqueous phase with organic compounds from the previous runs. Higher bio-oil yields are obtained when performing hydrothermal liquefaction with an aqueous phase loaded with light polar organics, probably because of condensation of those intermediates to form bio-oil. In addition, the presence of Maillard products in the reaction medium could prevent char formation from bio-oil degradation, therefore increasing the overall mass ratio between the oil and the char. The recovery of a free-flowing hydrophobic residue after a few recycles may be the result of a better bio-oil production, as well as the stabilization of amphiphilic compounds (fatty acids derivatives) into the bio-oil that could change the phase separation between the bio-oil and the aqueous phase. In addition, it suggests the possibility of developing a solvent-free process to recover bio-oil in high proportions and with high energy content. Yet, the bio-oil is rich in oxygen and nitrogen and therefore should be upgraded before any use for fuel applications. Our results indicate that HTL could benefit from recycling the organic load contained in the aqueous phase, addressing both environmental and economic issues. By recycling the aqueous phase as a reaction solvent, the volume of aqueous wastes is reduced. It could greatly reduce the post-treatment requirements, as well as reduce the use of fresh water needed to perform HTL. This may be interesting, or even imperative, for feedstocks requiring additional water to perform HTL (for moisture contents of $<85$ wt \%).

\section{ASSOCIATED CONTENT}

\section{S Supporting Information}

The Supporting Information is available free of charge on the ACS Publications website at DOI: 10.1021/acs.energyfuels.6b00441.

Summary of GC-MS analysis of the aqueous phases recovered from experimental runs $\mathrm{R}_{0}-\mathrm{R}_{5}$ (Table $\mathrm{S} 1$ ); summary of GC-MS analysis of the bio-oils recovered from experimental runs $\mathrm{R}_{0}-\mathrm{R}_{5}$ (Table $\mathrm{S} 2$ ) (PDF)

\section{AUTHOR INFORMATION}

\section{Corresponding Author}

*Tel.: +33438784026. Fax: +33438785251. E-mail: Maxime. Deniel@cea.fr.

\section{Notes}

The authors declare no competing financial interest.

\section{ACKNOWLEDGMENTS}

The authors would like to acknowledge financial support from the French Research National Agency ANR (LIQHYD project, Grant No. ANR-12-BIME-0003). The authors are also grateful to Marine Blanchin, Hélène Miller, Sébastien Thiery, and Julien Roussely for technical support and help on analysis of the products.

\section{NOMENCLATURE}

\section{Abbreviations}

GC-MS = gas chromatography - mass spectrometry

HTL = hydrothermal liquefaction

TGA = thermogravimetric analysis

\section{Variables}

$\mathrm{C}_{\mathrm{BO}}=$ carbon content in bio-oil (wt \%)

$C_{\mathrm{BC}}=$ carbon content in dry blackcurrant pomace (wt \%)

$C_{\mathrm{C}}=$ carbon content in char (wt \%)

$\mathrm{CR}_{\mathrm{A}}=$ carbon recovery in aqueous phase (wt \% of initial carbon)

$\mathrm{CR}_{\mathrm{BO}}=$ carbon recovery in the bio-oil (wt $\%$ of initial carbon)

$\mathrm{CR}_{\mathrm{C}}=$ carbon recovery in char (wt \% of initial carbon)

$\mathrm{CR}_{\mathrm{G}}=$ carbon recovery in gas (wt \% of initial carbon)

$\mathrm{CTA}=$ concentration of total carbon in the aqueous phase $\left(\mathrm{g} \mathrm{L}^{-1}\right)$

$\mathrm{CT}_{\mathrm{A} \text { recycled }}=$ concentration of total carbon in the recycled aqueous phase $\left(\mathrm{g} \mathrm{L}^{-1}\right)$

$\mathrm{ER}_{\mathrm{BO}}=$ energy recovery ratio in the bio-oil (\%)

$\mathrm{HHV}_{\mathrm{BO}}=$ higher heating value of the bio-oil $\left(\mathrm{MJ} \mathrm{kg}^{-1}\right)$

$\mathrm{HHV}_{\mathrm{BC}}=$ higher heating value of the dry blackcurrant pomace $\left(\mathrm{MJ} \mathrm{kg}^{-1}\right)$

$m_{\mathrm{BC}}=$ mass of dry blackcurrant pomace $(\mathrm{g})$

$m_{\mathrm{BO}}=$ mass of bio-oil $(\mathrm{g})$

$m_{\mathrm{C}}=$ mass of char $(\mathrm{g})$

$m_{\mathrm{G}}=$ mass of gas $(\mathrm{g})$

$m_{\mathrm{R}}=$ mass of raw organic residue $(\mathrm{g})$

$m(\mathrm{C})_{\mathrm{G}}=$ mass of carbon in gaseous phase $(\mathrm{g})$

$M(\mathrm{C})=$ molar mass of carbon $\left(\mathrm{g} \mathrm{mol}^{-1}\right)$

$M(C)=12 \mathrm{~g} \mathrm{~mol}^{-1}$ 
$M_{j}=$ molar mass of gaseous species $j\left(\mathrm{~g} \mathrm{~mol}^{-1}\right)$

$N_{\mathrm{C} j}=$ number of carbon atoms in gaseous species $j$

$P_{\mathrm{f}}=$ final pressure in the reactor $(\mathrm{Pa})$

$P_{\mathrm{i}}=$ initial pressure in the reactor $(\mathrm{Pa})$

$\mathrm{R}=$ ideal gas constant; $\mathrm{R}=8.314 \mathrm{~J} \mathrm{~K}^{-1} \mathrm{~mol}^{-1}$

$\mathrm{SSO}=$ proportion of solvent-soluble organics (wt \%)

$T_{\mathrm{f}}=$ final temperature in the reactor $(\mathrm{K})$

$T_{\mathrm{i}}=$ initial temperature in the reactor $(\mathrm{K})$

$V_{\mathrm{A}}=$ volume of aqueous phase $(\mathrm{L})$

$V_{\mathrm{A} \text { recycled }}=$ volume of recycled aqueous phase $(\mathrm{L})$

$V_{\mathrm{G}}=$ volume of gaseous phase in the reactor $\left(\mathrm{m}^{3}\right)$

$W_{\mathrm{R}}=$ water content of raw organic residue (wt \%)

$Y_{\mathrm{BO}}=$ bio-oil yield (wt \% of dry blackcurrant pomace)

$Y_{\mathrm{C}}=$ char yield (wt \% of dry blackcurrant pomace)

$Y_{\mathrm{G}}=$ gas yield (wt \% of dry blackcurrant pomace)

$y_{j}=$ molar fraction of gaseous species $j$

\section{REFERENCES}

(1) Toor, S. S.; Rosendahl, L.; Rudolf, A. Hydrothermal liquefaction of biomass: A review of subcritical water technologies. Energy 2011, 36 (5), 2328-2342.

(2) Peterson, A. A.; Vogel, F.; Lachance, R. P.; Froling, M.; Antal, M. J., Jr.; Tester, J. W. Thermochemical biofuel production in hydrothermal media: A review of sub- and supercritical water technologies. Energy Environ. Sci. 2008, 1 (1), 32-65.

(3) Elliott, D. C.; Biller, P.; Ross, A. B.; Schmidt, A. J.; Jones, S. B. Hydrothermal liquefaction of biomass: Developments from batch to continuous process. Bioresour. Technol. 2015, 178, 147-156.

(4) Weingärtner, H.; Franck, E. U. F. Supercritical Water as a Solvent. Angew. Chem., Int. Ed. 2005, 44 (18), 2672-2692.

(5) Pedersen, T. H.; Grigoras, I. F.; Hoffmann, J.; Toor, S. S.; Daraban, I. M.; Jensen, C. U.; Iversen, S. B.; Madsen, R. B.; Glasius, M.; Arturi, K. R.; Nielsen, R. P.; Søgaard, E. G.; Rosendahl, L. A. Continuous hydrothermal co-liquefaction of aspen wood and glycerol with water phase recirculation. Appl. Energy 2016, 162, 1034-1041.

(6) López Barreiro, D.; Prins, W.; Ronsse, F.; Brilman, W. Hydrothermal liquefaction (HTL) of microalgae for biofuel production: State of the art review and future prospects. Biomass Bioenergy 2013, 53, 113-127.

(7) Déniel, M.; Haarlemmer, G.; Roubaud, A.; Weiss-Hortala, E.; Fages, J. Energy valorisation of food processing residues and model compounds by hydrothermal liquefaction. Renewable Sustainable Energy Rev. 2016, 54, 1632-1652.

(8) Vardanega, R.; Prado, J. M.; Meireles, M. A. A. Adding value to agri-food residues by means of supercritical technology. J. Supercrit. Fluids 2015, 96, 217-227.

(9) Viganó, J.; Da Fonseca Machado, A. P.; Martínez, J. Sub- and supercritical technology applied to food waste processing. J. Supercrit. Fluids 2015, 96, 272-286.

(10) Food and Agriculture Organization of the United Nations. Food Wastage Footprint: Full-Cost Accounting. Final Report; 2014. (ISBN 978-92-5-108513-4.)

(11) European Commission. Final Report-Preparatory Study on Food Waste across EU27; Technical Report No. 2010-054; 2010. (ISBN 978-92-79-22138-5.)

(12) Food and Agriculture Organization of the United Nations. Global Initiative on Food Loss and Waste Reduction; 2014.

(13) Cherad, R.; Onwudili, J. A.; Biller, P.; Williams, P. T.; Ross, A. B. Hydrogen production from the catalytic supercritical water gasification of process water generated from hydrothermal liquefaction of microalgae. Fuel 2016, 166, 24-28.

(14) Hognon, C.; Delrue, F.; Texier, J.; Grateau, M.; Thiery, S.; Miller, H.; Roubaud, A. Comparison of pyrolysis and hydrothermal liquefaction of Chlamydomonas reinhardtii. Growth studies on the recovered hydrothermal aqueous phase. Biomass Bioenergy 2015, 73 (0), 23-31.
(15) Xia, R.; Na, D.; Zhang, Y. H.; Baoming, L.; Zhidan, L.; Lu, H. F. Nitrogen and phosphorous adsorption from post-hydrothermal liquefaction wastewater using three types of zeolites. Int. J. Agric. Biol. Eng. 2015, 8 (5), 86-95.

(16) Wirth, B.; Mumme, J. Anaerobic Digestion of Waste Water from Hydrothermal Carbonization of Corn Silage. Appl. Bioenergy 2013, 1 (1).10.2478/apbi-2013-0001

(17) Danso-Boateng, E.; Shama, G.; Wheatley, A. D.; Martin, S. J.; Holdich, R. G. Hydrothermal carbonisation of sewage sludge: Effect of process conditions on product characteristics and methane production. Bioresour. Technol. 2015, 177 (0), 318-327.

(18) Wirth, B.; Reza, T.; Mumme, J. Influence of digestion temperature and organic loading rate on the continuous anaerobic treatment of process liquor from hydrothermal carbonization of sewage sludge. Bioresour. Technol. 2015, 198, 215-222.

(19) Kumar, S.; Lange, J.-P.; Van Rossum, G.; Kersten, S. R. A. Liquefaction of Lignocellulose: Process Parameter Study To Minimize Heavy Ends. Ind. Eng. Chem. Res. 2014, 53 (29), 11668-11676.

(20) Li, C.; Yang, X.; Zhang, Z.; Zhou, D.; Zhang, L.; Zhang, S.; Chen, J. Hydrothermal Liquefaction of Desert Shrub Salix psammophila to High Value-added Chemicals and Hydrochar with Recycled Processing Water. Bioresources 2013, 8 (2). Available via the Internet at: http://ojs.cnr.ncsu.edu/index.php/BioRes/article/view/ BioRes_08_2_2981_Li_Hydrothermal_Salix.

(21) $\bar{Z}$ hu, $\bar{Z}$.; Rosendahl, L.; Toor, S. S.; Yu, D.; Chen, G. Hydrothermal liquefaction of barley straw to bio-crude oil: Effects of reaction temperature and aqueous phase recirculation. Appl. Energy 2015, 137, 183-192.

(22) Ramos-Tercero, E. A.; Bertucco, A.; Brilman, D. W. F. Process Water Recycle in Hydrothermal Liquefaction of Microalgae To Enhance Bio-oil Yield. Energy Fuels 2015, 29 (4), 2422-2430.

(23) Anouti, S.; Haarlemmer, G.; Déniel, M.; Roubaud, A. Analysis of physicochemical properties of bio-oil from hydrothermal liquefaction of blackcurrant pomace. Energy Fuels 2016, 30, 398.

(24) Speight, J. G. Distillation. In Handbook of Petroleum Product Analysis: Wiley-Interscience: New York, 2001.

(25) Zhou, D.; Zhang, L.; Zhang, S.; Fu, H.; Chen, J. Hydrothermal Liquefaction of Macroalgae Enteromorpha prolifera to Bio-oil. Energy Fuels 2010, 24 (7), 4054-4061.

(26) Zhang, B.; Von Keitz, M.; Valentas, K. Thermochemical liquefaction of high-diversity grassland perennials. J. Anal. Appl. Pyrolysis 2009, 84 (1), 18-24.

(27) Cheng, X.; Ooms, M. D.; Sinton, D. Biomass-to-biocrude on a chip via hydrothermal liquefaction of algae. Lab Chip 2016, 16 (2), 256-260.

(28) Minowa, T.; Inoue, S.; Hanaoka, T.; Matsumura, Y. Hydrothermal reaction of glucose and glycine as model compounds of biomass. Nippon Enerugi Gakkaishi 2004, 83 (10), 794-798.

(29) Kruse, A.; Maniam, P.; Spieler, F. Influence of Proteins on the Hydrothermal Gasification and Liquefaction of Biomass. 2. Model Compounds. Ind. Eng. Chem. Res. 2007, 46 (1), 87-96.

(30) Peterson, A. A.; Lachance, R. P.; Tester, J. W. Kinetic Evidence of the Maillard Reaction in Hydrothermal Biomass Processing: Glucose-Glycine Interactions in High-Temperature, High-Pressure Water. Ind. Eng. Chem. Res. 2010, 49 (5), 2107-2117.

(31) Faeth, J. L.; Jarvis, J. M.; McKenna, A. M.; Savage, P. E. Characterization of Products from Fast and Isothermal Hydrothermal Liquefaction of Microalgae. AIChE J. 2016, 62 (3), 815-828. 